\title{
p53 and MIB-1 Immunohistochemistry as Predictors of the Clinical Behavior of Nonfunctioning Pituitary Adenomas
}

\author{
Stephen J. Hentschel, Ian E. McCutcheon, Wayne Moore, Felix A. Durity
}

\begin{abstract}
Background: P53 expression and increased MIB-1 proliferation index have been shown to correlate with invasive behavior in pituitary adenomas. The purpose of this study was to determine whether these indices could be used to predict a higher likelihood of recurrence in clinically nonfunctional pituitary adenomas and thus guide adjuvant therapy. Methods: Fifty-one clinically nonfunctional pituitary adenomas were selected from the database at the Vancouver Hospital and Health Sciences Center between the years 1990-1998. Included were 32 nonrecurrent and 19 recurrent adenomas. Results: The mean initial labelling index for p53 in nonrecurrent tumours was $0.38 \%(0-1.58 \%)$, while it was $0.46 \%(0-3.65 \%)$ for recurrent adenomas. The mean initial MIB-1 index for nonrecurrent tumours was $1.63 \%(0.08-9.36 \%)$, while for recurrent tumours it was $1.92 \%(0-7.76 \%)$. The percentage of p53 positive adenomas was $66 \%$ for nonrecurrent tumours and $68 \%$ for recurrent tumours. None of the differences in the labelling indices between the recurrent and nonrecurrent groups was statistically significant. As 12 patients (38\%) in the nonrecurrent group had undergone radiotherapy as initial adjuvant therapy after surgery and none of the recurrent group had done so, patients who did not receive radiotherapy in the nonrecurrent group were analyzed separately. Again, none of the differences in the labelling indices between the recurrent and nonrecurrent groups was statistically significant when the effect of radiotherapy was removed from the analysis. Conclusions: The results demonstrate no statistical difference in the p53 or MIB-1 labelling indices between recurrent and nonrecurrent nonfunctional pituitary adenomas. Concern should be raised in attaching too much clinical significance to these labelling indices, especially with respect to p53 as a predictor of the clinical behavior of nonfunctional pituitary adenomas.
\end{abstract}

RÉSUMÉ: Immunohistochimie par marquage de la p53 et de MIB-1 pour prédire le comportement clinique des adénomes hypophysaires non fonctionnels. Introduction: Dans les adénomes hypophysaires, il existe une corrélation entre un comportement envahissant de la tumeur et l'expression de la p53 et une augmentation de l'index de prolifération MIB-1. Le but de cette étude était de déterminer si ces indices pouvaient être utilisés pour prédire le risque de récidive des adénomes hypophysaires cliniquement non fonctionnels et ainsi guider le traitement adjuvant. Méthodes: Cinquante et un adénomes hypophysaires cliniquement non fonctionnels, dont 32 étaient non récurrents et 19 récurrents, ont été sélectionnés dans la base de données du Vancouver Hospital et du Health Sciences Center entre 1990 et 1998. Résultats: L'index de marquage initial moyen pour la p53 était de 0,38\% pour les tumeurs non récurrentes (0-1,58\%) et de 0,46\% (0-3,65\%) pour les adénomes récurrents. L'index MIB-1 initial moyen pour les tumeurs non récurrentes était de 1,63\% (0,08-9,36\%) et de 1,92\% (0-7,76\%) pour les tumeurs récurrentes. Soixante-six pour cent des adénomes non récurrents et $68 \%$ des adénomes récurrents étaient positifs pour la p53. Aucune des différences entre les indices de marquage entre les deux groupes n'atteignait le seuil de significativité. Étant donné que 12 patients (38\%) du groupe ayant un adénome non récurrent avaient subi de la radiothérapie comme traitement adjuvant initial après la chirurgie et qu'aucun n'en avait reçu dans le groupe ayant un adénome récurrent, les données des patients qui n'ont par reçu de radiothérapie dans le groupe ayant un adénome non récurrent ont été analysées séparément. Aucune des différences entre les deux groupes dans les indices de marquage n'atteignait le seuil de significativité quand l'effet de la radiothérapie était retiré de l'analyse. Conclusions: Ces résultats ne démontrent aucune différence statistique dans les indices de marquage par l'anticorps de la p53 et de MIB-1 entre les adénomes hypophysaires non fonctionnels récurrents et non récurrents. On doit se garder d'attribuer une trop grande signification clinique à ces indices de marquage, surtout quant à la p53, pour prédire l'évolution clinique des adénomes hypophysaires non fonctionnels.

Can. J. Neurol. Sci. 2003; 30: 215-219

Mutations in the p53 gene are the most commonly identified genomic alterations in human cancers. ${ }^{1}$ For example, patients with the Li-Fraumeni cancer syndrome have germ-line mutations in the p53 gene and have a significant risk of developing breast carcinomas, sarcomas, and other neoplasms at an early age. p53 has been studied in a wide variety of human neoplasms, including breast cancer, ${ }^{2}$ colonic carcinomas, ${ }^{3}$ Hodgkin's disease, ${ }^{4}$ and hepatic neoplasms, ${ }^{5}$ as well as in central nervous
From the Division of Neurosurgery, Department of Surgery, University of British, Columbia, Vancouver Hospital and Health Sciences Centre, Vancouver, BC, Canada (SJH, FAD); Department of Neurosurgery, University of Texas, M.D. Anderson Cancer Center, Houston, Texas, USA (SJH, IEM); Division of Neuropathology, Department of Pathology and Laboratory Medicine, Vancouver Hospital and Health Sciences Centre, University of British Columbia, Vancouver, BC, Canada (WM).

ReCEIVED MAY 15, 2002. ACCEPTED IN FINAL FORM DECEMBER 19, 2002.

Reprint requests to: Felix Durity, Department of Surgery, Division of Neurosurgery, 910 West 10th Ave, 3rd Floor, Vancouver, BC V5Z 4E3 Canada 
system tumours such as meningiomas, ${ }^{6}$ gliomas, ${ }^{7-9}$ and pituitary adenomas. ${ }^{10-19}$

The wild-type p53 gene is located on the short arm of chromosome 17 and functions as a cell cycle regulator. ${ }^{20}$ p53 is involved in arresting the cell cycle in the $G_{1}$ phase of growth, in the initiation of DNA repair, in the induction of apoptosis, and in the promotion of cellular differentiation. ${ }^{21}$ The p53 protein product in its wild-type form has a short half-life and is difficult to detect through standard immunohistochemical techniques, while the mutated forms are more stable, have a longer half-life, and are detectable with standard techniques in immunohistochemistry. $^{22,23}$

MIB-1, an antibody which recognizes the Ki-67 antigen present in cells in the proliferative phase, is utilized as a measure of proliferative activity. ${ }^{24}$ The MIB- 1 antibody recognizes this epitope in formalin-fixed paraffin-embedded tissue, allowing immunohistochemistry for cell proliferation to be performed on routinely processed surgical specimens. This immunohistochemical technique has been applied to a variety of cerebral neoplasms, ${ }^{25}$ and more specifically to pituitary tumours. ${ }^{11,13,14,19,26-29}$

Clinically, nonfunctional pituitary adenomas include several different tumour types that can be classified based on cytological or ultrastructural characteristics, however none is associated with a clinically definable syndrome of hormonal excess. ${ }^{30}$ These tumours are distinct from functional adenomas in that there is usually no measurable product (except in the alpha-subunit secreting tumors ${ }^{31}$ ) that may be used to follow or to predict the recurrence of these tumours. It would be useful to determine which nonfunctional tumours will act in a clinically aggressive manner and thus require adjuvant therapy. Previous studies of mixed functional and nonfunctional tumours have identified a higher incidence of p53 positivity and increased MIB-1 labelling index in invasive adenomas. ${ }^{12,28}$

The purpose of this study was to further define the clinical usefulness of p53 and MIB-1 in predicting recurrence or aggressive clinical behavior in clinically nonfunctional pituitary adenomas.

\section{MethodS}

\section{Patients}

The Vancouver Hospital and Health Sciences Centre database was searched for patients with clinically nonfunctional pituitary adenomas between the years 1990-1998. During this time period there were 25 recurrent nonfunctional adenomas within the group of 245 patients with nonfunctional adenomas. There were no malignant tumours identified amongst the total group of adenomas. A group consisting of 32 nonfunctional nonrecurrent adenomas was randomly selected by a computer from the database. The patients' clinical records were then reviewed for details of operative and adjuvant therapies, results of imaging, time to recurrence, and status of the tumour at last follow-up. There were six patients with known recurrent tumours whose initial pathology/immunohistochemistry was unavailable for review as it could not be retrieved from another center $(n=5)$ or our own centre $(n=1)$, thus the recurrent $(n=19)$ and nonrecurrent $(n=32)$ populations included a total of 51 patients.

For the purposes of this study, an invasive adenoma was defined as one with involvement of the cavernous sinus, erosion through the clivus or into the middle cranial fossa, or invasion of the sphenoid sinus with breached dura. ${ }^{32}$ All patients were routinely followed, and a recurrent tumour was defined as growth of residual disease where dormancy had previously been demonstrated on follow-up imaging or regrowth of tumour where none had been visualized previously on routine postoperative imaging.

A nonfunctional adenoma was defined as one producing no clinically evident syndrome such as Cushing's Syndrome or acromegaly as well as no measurable elevation of thyroid stimulating hormone (TSH), luteinizing hormone ( $\mathrm{LH})$, follicle stimulating hormone (FSH), growth hormone $(\mathrm{GH})$, insulin growth factor 1 (IGF-1), or cortisol. However, patients were included who had mild elevations in the prolactin level (PRL) (generally $<100 \mathrm{ng} / \mathrm{ml}$ ) secondary to the 'stalk effect'.

\section{Immunohistochemistry}

Tumour samples were routinely fixed in formalin, dehydrated, and embedded in paraffin. Sections ( $3 \mu \mathrm{m}$ thickness) were mounted onto Silane-coated glass slides. Immunocytochemistry was then carried out using an automated avidin-biotin system (Ventana ES, Ventana Medical Systems, Tucson, AZ) employing MIB-1 monoclonal antibody diluted 1:200 (Immunotech, France) or p53 antibody diluted 1:400 (Dako, Glastrop, Denmark).

All p53 and MIB-1 counts were performed by one of the authors $(\mathrm{SH})$ in blinded fashion. Non-overlapping high power fields of the densest areas of positivity were photographed on a microscope (40X magnification) using a high-resolution digital camera, imported into a computer, and counted on a large monitor. The fields were counted until at least 1000 cells had been tallied and the labelling index was reported as the percentage of positively labelled cells. Although the intensity of immunostaining varied, all cells demonstrating definite nuclear positivity were counted, in keeping with counting techniques described by other authors (Figure). ${ }^{12,33}$

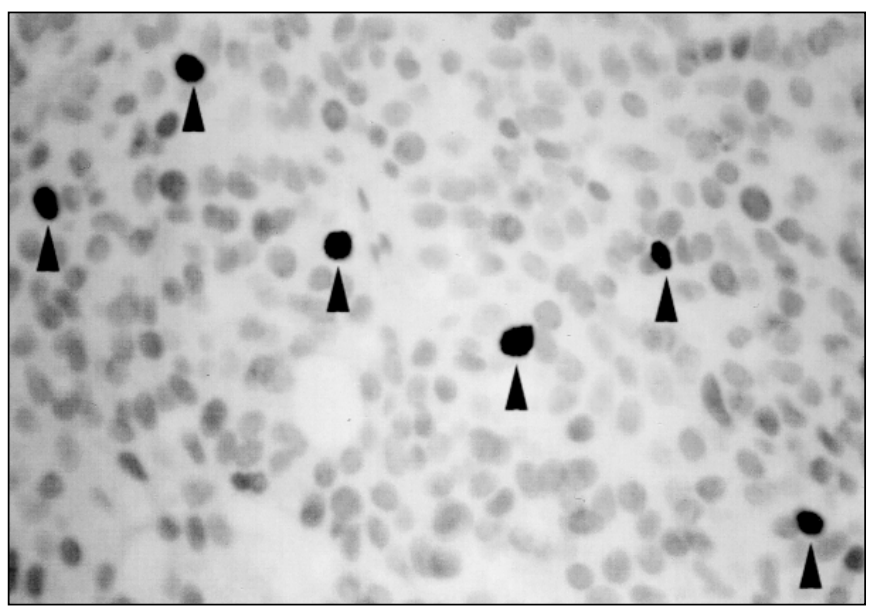

Figure: Photomicrograph (40X magnification) demonstrating p53 nuclear positivity (black arrows) with the background nuclei lightly counterstained with hematoxylin. 
Table 1: Epidemiological characteristics of three groups of adenomas

\begin{tabular}{lccl}
\hline & Nonrecurrent & $\begin{array}{c}\text { Nonrecurrent } \\
\text { (no radiation) }\end{array}$ & Recurrent \\
Number & 32 & 20 & 19 \\
Age (mean years) & 55 & 57 & 49 \\
Sex: Female & 19 & 12 & 9 \\
$\quad 13$ & 8 & 10 \\
$\quad$ Male & 31 & 31 & 32 \\
Size (mean mm) & $12(38 \%)$ & 0 & 0 \\
Radiotherapy (initial) & $14(44 \%)$ & $4(20 \%)$ & $6(32 \%)$ \\
Invasive & $24(75 \%)$ & $12(60 \%)$ & $14(74 \%)$ \\
Post-op residual (initial) & & & 2.4 \\
Time to recur (mean years) & & & $0.5-6.1$ \\
$\quad$ range (years) & 3.7 & 3.0 & 5.5 \\
Follow-up (mean years) & $0.3-9.1$ & $0.3-8.8$ & $1.4-13.8$ \\
$\quad$ range (years) & & & \\
\end{tabular}

Table 2: Labelling characteristics of recurrent and non-recurrent adenomas at the time of the first surgery (the total non-recurrent group and the subgroup without initial radiotherapy)

\begin{tabular}{llcl}
\hline & Nonrecurrent & $\begin{array}{l}\text { Nonrecurrent } \\
\text { (no radiation) }\end{array}$ & Recurrent \\
Number & 32 & 20 & 19 \\
p53 Positive & $21(66 \%)$ & $11(55 \%)$ & $13(68 \%)$ \\
p53 Index (mean)* & $0.38 \%$ & $0.28 \%$ & $0.46 \%$ \\
$\quad$ range & $0-1.58 \%$ & $0-1.02 \%$ & $0-3.65 \%$ \\
MIB-1 Index (mean)* & $1.63 \%$ & $1.89 \%$ & $1.92 \%$ \\
$\quad$ range & $0.08-9.36 \%$ & $0.08-9.36 \%$ & $0-7.76 \%$ \\
& & & \\
\hline
\end{tabular}

*differences in the labelling indices were not statistically significant

\section{Statistical analysis}

Analysis of the data was performed utilizing a Mann-Whitney test for independent samples. The level of statistical significance was considered to be less than 0.05 in all cases. No correction for multiple comparisons was performed as there were no comparisons that yielded a statistically significant difference.

\section{RESUlts}

\section{Recurrent versus nonrecurrent adenomas}

There were 32 nonrecurrent and 19 recurrent nonfunctional adenomas for which the initial pathology was available for review and immunohistochemical staining (Table 1). None of the differences in the labelling indices between the recurrent and nonrecurrent groups was statistically significant (Table 2).

As 12 patients (38\%) in the nonrecurrent group underwent radiotherapy as initial adjuvant therapy, at the discretion of the treating surgeon, and none of the recurrent group had done so, patients who did not receive radiotherapy in the nonrecurrent group were analyzed separately (Table 1). Exclusion of the radiated group did not alter the results and again there was no statistically significant difference between the labelling indices. As well, there was no substantial difference between the three groups described above in terms of patient age, sex, tumour size, invasiveness, or presence of postoperative residual.

\section{Hormonal immunohistochemistry}

Despite the absence of a clinically definable hypersecretory syndrome in all patients, many of the tumours stained positive by immunohistochemistry for some hormones. In no case was there strong, diffuse positivity for pituitary hormones and particular patterns of mild focal staining were evident: 1) positivity for TSH, FSH, and LH, always with all three in combination; 2) positivity for GH and PRL in combination; 3) isolated positivity for ACTH; or uncommonly, 4) combinations of the above. Testing for $\alpha$-subunit was not performed.

\section{Discussion}

Although most pituitary adenomas are histologically benign, their behavior can be more aggressive, with multiple recurrences requiring multiple therapeutic strategies for tumour control. If it were possible to predict which pituitary adenomas were more biologically aggressive and thus more likely to recur, adjuvant therapy could be utilized to treat those patients who harboured the more aggressive adenomas and withheld if the tumour was predicted to behave more indolently. Unfortunately, routine histology (hematoxylin and eosin) is not useful in identifying higher grade neoplasms which may require adjuvant therapy. ${ }^{34}$ It has previously been shown that p53 and MIB-1 levels seem to correlate with invasiveness in pituitary adenomas, ${ }^{10,12,28,35}$ but no particularly good correlation with clinical behavior occurs from patient to patient. ${ }^{11,29}$

\section{Previous studies}

A previous study of functional and nonfunctional tumours found mean MIB-1 labelling indices of $1.37 \%, 4.66 \%$, and $11.91 \%$ for noninvasive adenomas, invasive adenomas, and pituitary carcinomas, respectively. ${ }^{28}$ Invasiveness was defined by radiographic and intraoperative findings. A threshold labelling index of $3 \%$ was established to differentiate noninvasive adenomas from potentially invasive ones. The MIB-1 labelling index of nonfunctional adenomas was lower (2.06\%) than functional adenomas (3.25\%). Unfortunately, 'invasive' is a subjective descriptor with several definitions and thus the reported proportion of adenomas that are invasive varies widely between 5-67\%, depending on the study. ${ }^{32,36-39}$ However, it has been shown that invasive features do correlate with poorer rates of tumour control and more aggressive biologic behavior. This applies mainly to functional adenomas, ${ }^{13,40,41}$ and the relationship is not as clear for nonfunctional adenomas. ${ }^{32} \mathrm{~A}$ recent study found that the MIB-1 labelling index was not predictive of tumour recurrence for nonfunctional adenomas, however, invasiveness was correlated with increased likelihood of tumour recurrence. ${ }^{29}$ Knosp et $\mathrm{al}^{35}$ found that MIB-1 rates correlated with dural invasiveness, but it has been shown that dural invasion alone is not predictive of a more aggressive 
tumour. $^{38}$ Buchfelder et $\mathrm{al}^{11}$ found a positive relationship between invasiveness and the MIB-1 labelling index, but offered no data to support its usefulness in a clinical situation. Other studies have failed to find a positive correlation between invasion and increased MIB-1 labelling indices. ${ }^{27,42}$

In another study examining the relationship between p53 and invasiveness for various functional and nonfunctional tumours, it was found that for noninvasive and invasive adenomas and for pituitary carcinomas, the rates of p53 positivity were $0 \%, 15.2 \%$, and $100 \%$, respectively. ${ }^{12}$ In that study it appeared to be absolute p53 positivity rather than the extent of positivity that was important, as the p53 labelling index of $1.8 \%$ was similar for both invasive adenomas and pituitary carcinomas. Thus, it was implied that a single positive cell for p53 could significantly predict the biologic behavior of the whole adenoma. The rate of p53 positivity varies widely throughout the literature, depending on what type of adenoma is being examined, from $0 \%$ for noninvasive adenomas to $88 \%$ for pituitary carcinomas. ${ }^{10,14,17,27}$ Buckley et $\mathrm{al}^{10}$ found six of 26 nonfunctional invasive adenomas were p53 positive, while none of 33 noninvasive adenomas were positive. Gandour-Edwards et $\mathrm{al}^{19}$ could not identify any p53 positive tumours in six invasive or in six noninvasive nonfunctional adenomas.

\section{Recurrent versus nonrecurrent adenomas}

There was no statistical difference for p53 labelling index, absolute p53 positivity, or MIB-1 labelling index between nonrecurrent and recurrent adenomas. A similar result for MIB-1 labelling index had been found previously ${ }^{29,42}$ but the clinical usefulness of p53 has not been previously examined in detail in the English literature. The mean follow-up for nonrecurrent adenomas is less than that for recurrent adenomas (3.7 and 5.5 years, respectively), however the mean time to recurrence is 2.4 years in this study with only three of 19 patients recurring at over 3.7 years. Thus, the longer follow-up in the recurrent group likely indicates a more complicated management protocol, although this may also be a confounding factor as tumours that are followed longer may be more likely to recur.

\section{Hormonal immunohistochemistry}

Although there were particular patterns of hormonal staining in these clinically nonfunctional adenomas, it is clear that no particular hormonal type is overly represented in the recurrent group when compared with the nonrecurrent group.

\section{Variability of labelling indices}

It is not certain what biological event is being measured with p53 immunohistochemical techniques. In a study of 29 adenomas which included 15 noninvasive and nonfunctioning tumours, Levy et al $^{18}$ could not identify p53 mutations using genetic analysis to screen the usual locations in any of the tumours despite five being positive for p53 by immunohistochemical techniques. He and other authors have concluded that the immunohistochemical detection of p53 has no correlation with the presence of p53 mutations. ${ }^{15,43,44}$ Clayton has stated that "... it is clear that abnormalities in this protein, which is so frequently involved in pathogenesis $(50 \%$ of common tumours), has little part to play in the majority of pituitary tumours." 44 It is possible either that p53 immunohistochemistry detects abnormalities in the p53 protein unrelated to p53 genetic mutations or that genetic mutations occur at higher frequency than previously expected at other locations not screened in these genetic analyses. If disturbances in p53 regulation unrelated to mutation are being detected by immunohistochemistry, then this may still be important in adenoma pathogenesis. If, however, a mutation resulted in loss of p53 function, then it would be possible that significant dysfunction in p53 regulation could be present and yet not be detected by immunohistochemistry. ${ }^{18}$ Overexpression of wildtype p53 (in reaction to neoplasia) may also lead to its detection by immunohistochemistry. ${ }^{43}$ Given these reservations and given the results of the current study, caution should be raised about the clinical value of conventional p53 immunohistochemistry in nonfunctional pituitary adenomas.

The results reported here demonstrate no statistical difference, and certainly no clinically useful predictive difference, in the p53 or MIB-1 labelling indices between recurrent and nonrecurrent nonfunctional pituitary adenomas. Concern should be raised in placing too much clinical emphasis on these labelling indices, especially with respect to p53.

\section{ACKNOWLEDGEMENTS}

We thank Beverley Dupuis and the staff of the immunohistochemistry laboratory at the Vancouver Hospital and Health Sciences Centre for their technical assistance.

\section{REFERENCES}

1. Hollstein M, Sidransky D, Vogelstein B, Harris C. p53 mutations in human cancer. Science 1991;256:49-53

2. Pietilainen T, Lipponen P, Aaltomaa S, et al. Expression of p53 protein has no independent prognostic value in breast cancer. J Pathol 1995; 177:225-232.

3. Baas I, Mulder J, Offerhaus G, et al. An evaluation of six antibodies for immunohistochemistry of mutant p53 gene product in archival colorectal neoplasms. J Pathol 1994;172:5-12.

4. Xerri L, Bouabdallah R, Camerlo J, Hassoun J. Expression of the p53 gene in Hodgkin's disease: dissociation between immunohistochemistry and clinicopathological data. Hum Pathol 1994;25:449-454.

5. Kennedy S, MacGeogh C, Jaffe R, Spurr N. Overexpression of the oncoprotein p53 in primary hepatic tumors of childhood does not correlate with gene mutations. Hum Pathol 1994;25:438-442.

6. Cho H, Ha S, Park S, et al. Role of p53 gene mutation in tumor aggressiveness of intracranial meningiomas. J Korean Med Sci 1999; 14:199-205.

7. Kyritsis A, Bondy M, Hess K, et al. Prognostic significance of p53 immunoreactivity in patients with glioma. Clin Cancer Res 1995;1:1617-1622.

8. Chozick B, Pezzullo J, Epstein M, Finch P. Prognostic implications of p53 overexpresion in supratentorial astrocytic tumors. Neurosurgery 1994;35:831-838.

9. Montine $\mathrm{T}$, Bruner J, Vandersteenhoven J, et al. Prognostic significance of p53 immunoreactivity in adult patients with supratentorial fibrillary astrocytic neoplasms. Diagn Mol Pathol 1994;3:240-245.

10. Buckley N, Bates A, Broome J, et al. p53 protein accumulates in Cushing's adenomas and invasive nonfunctional adenomas. [corrected and republished article originally printed in J Clin Endocrinol Metab 1994;79(5):1513-1516] J Clin Endocrinol Metab 1995;80:4 pages following 692.

11. Buchfelder M, Fahlbusch R, Adams E, et al. Proliferation parameters for pituitary adenomas. Acta Neurochir (Wien) 1996;65 (Suppl):18-21.

12. Thapar K, Scheithauer B, Kovacs K, et al. p53 expression in pituitary adenomas and carcinomas: correlation with 
invasiveness and tumor growth fractions. Neurosurgery 1996;38:765-771.

13. Blevins L, Verity D, Allen G. Aggressive pituitary tumours. Oncology 1998;12:1307-1315.

14. Pernicone P, Scheithauer B, Sebo T, et al. Pituitary carcinoma. Cancer 1997:79:804-812.

15. Herman V, Drazin N, Gonsky R, Melmed S. Molecular screening of pituitary adenomas for gene mutations and rearrangements. J Clin Endocrinol Metab 1993;77:50-55.

16. Perrett C, Clayton R, Pistorello M, et al. GSTM1 and CYP2D6 genotype frequencies in patients with pituitary tumours: effects on p53, ras and gsp. Carcinogenesis 1995;16:1643-1645.

17. Green V, White M, Hipkin L, et al. Apoptosis and p53 suppressor gene protein expression in human anterior pituitary adenomas. Eur J Endocrinol 1997;136:382-387.

18. Levy A, Hall L, Yeudall W, Lightman S. p53 gene mutations in pituitary adenomas: rare events. Clin Endocrinol (Oxf) 1994;41:809-814.

19. Gandour-Edwards R, Kapadia S, Janecka I, et al. Biologic markers of invasive pituitary adenomas involving the sphenoid sinus. Mod Pathol 1995;8:160-164.

20. Litofsky N, Recht L. The impact of p53 tumor suppresor gene on glioma biology. Neurosurg Focus. 1997;3:Article 4.

21. Louis D. The p53 gene and protein in human brain tumors. J Neuropathol Exp Neurol 1994;53:11-21.

22. Levine A, Momand J, Finlay C. The p53 tumor suppressor gene. Nature 1991;351:453-456.

23. Harris C, Hollstein M. Clinical implications of the p53 tumorsuppressor gene. N Engl J Med 1993;329:1318-1327.

24. Gerdes J, Lemke H, Baisch H, et al. Cell cycle analysis of a cell proliferation-associated human nuclear antigen defined by the monoclonal antibody Ki-67. J Immunol 1984;133:1710-1715.

25. Jaros E, Perry R, Adam L, et al. Prognostic implications of p53 protein, epidermal growth factor receptor, and Ki-67 labelling in brain tumours. Br J Cancer 1992;66:373-385.

26. Miyagami M, Nakamura S. Significance of p53 protein expression and proliferative potential with MIB-1 on tumor recurrence of pituitary adenomas. No To Shinkei 1998;50:27-32.

27. Muller W, Saeger W, Wellhausen L, et al. Markers of function and proliferation in noninvasive and invasive bi- and plurihormonal adenomas of patients with acromegaly: an immunohistochemical study. Pathol Res Pract 1999;195:595-603.

28. Thapar K, Kovacs K, Scheithauer B, et al. Proliferative activity and invasiveness among pituitary adenomas and carcinomas: an analysis using the MIB-1 antibody. Neurosurgery 1996;38:99-107.

29. Losa M, Frankin A, Mangili F, et al. Proliferation index of nonfunctioning pituitary adenomas: correlations with clinical characteristics and long-term follow-up results. Neurosurgery 2000;47:1313-1319.

30. Asa S, Kovacs K. Clinically nonfunctioning human pituitary adenomas. Can J Neurol Sci 1992;19:228-235.

31. Samejima N, Yamada S, Takada K, et al. Serum $\alpha$-subunit levels in patients with pituitary adenomas. Clin Endocrinol (Oxf) 2001;54:479-484.

32. Ciric I, Mikhael M, Stafford T, et al. Transsphenoidal microsurgery of pituitary macroadenomas with long-term follow-up results. J Neurosurg 1983;59:395-401.

33. Gee J, Douglas-Jones A, Hepburn P, et al. A cautionary note regarding the application of $\mathrm{Ki}-67$ antibodies to paraffinembedded breast cancers. J Pathol 1995;177:285-293.

34. Pegolo G, Buckwalter J, Weiss M. Pituitary adenomas: correlation of the cytologic appearance with biologic behavior. Acta Cytol 1995;39:887-892.

35. Knosp E, Kitz K, Perneczky A. Proliferation activity in pituitary adenomas: measurement by monoclonal antibody Ki-67. Neurosurgery 1989;25:927-930.

36. Ebersold M, Quast L, ER Laws J, et al. Long-term results in transsphenoidal removal of nonfunctioning pituitary adenomas. J Neurosurg 1986;64:713-719.

37. Scheithauer B, Kovacs K, ER Laws J, Randall R. Pathology of invasive pituitary tumors with special reference to functional classification. J Neurosurg 1986;65:733-744.

38. Selman W, ER Laws J, Scheithauer B, Carpenter S. The occurence of dural invasion in pituitary adenomas. $\mathrm{J}$ Neurosurg 1986;64:402-407.

39. Sautner D, Saeger W. Invasiveness of pituitary adenomas. Pathol Res Pract 1991;187:632-636.

40. Mindermann T, Wilson C. Thyrotropin-producing pituitary adenomas. J Neurosurg 1993;79:521-527.

41. Fahlbusch R, Honneger J, Buchfelder M. Surgical management of acromegaly. Endocrinol Metab Clin North Am 1992;21:669-692.

42. Yonezawa K, Tamaki N, Kokunai T. Clinical features and growth fractions of pituitary adenomas. Surg Neurol 1997;48:494-500.

43. Battifora H. p53 immunohistochemistry: a word of caution. Hum Pathol 1994;25:435-436.

44. Clayton R, Boggild M, Bates A, et al. Tumour suppressor genes in the pathogenesis of human pituitary tumours. Horm Res 1997; 47:185-193. 